\title{
Regulation strategies and their impact on subsequent response inhibition: the moderating role of the self-control trait
}

\author{
Natalia Wójcik (DD A,B,C,D,E,F, Edward Nęcka (DD ${ }^{D, E, G}$ \\ Institute of Psychology, Faculty of Philosophy, Jagiellonian University, Krakow, Poland
}

\section{BACKGROUND}

Much research has shown that effortful acts of self-contro temporarily impair its subsequent exertion. The aim of our experiment was to examine whether this effect, called ego depletion, is influenced by application of certain strategies that help people to overcome impulses. Another purpose of our research was to investigate the role of self-control as a trait in this area. We focused on amusement regulation because of its importance in everyday life.

PARTICIPANTS AND PROCEDURE

Participants $(N=90)$ completed the Self-Control Scale (NAS-50) and were then asked to rate humorous cartoons (Task 1) while inducing the following self-regulatory strategies suggested by the instructions: cognitive change, response inhibition, or none (between-subjects manipulation). Subsequently, participants performed the Stop Signal Task (Task 2).

\section{RESULTS}

The results indicate that the depletion effect is absent unless trait self-control is included in the analysis. We ob- served the interaction between the self-control trait and the effectiveness of the adopted self-regulatory strategy. Participants with poor self-control did not differ in their performance in Task 2, regardless of the adopted strategy. With the increase in the self-control trait, we observed differences in Task 2 that indicated that the cognitive change strategy guarded against depletion in participants with a medium level of self-control. Participants with a high self-control trait level obtained better scores in both regulatory groups, compared to the condition without any strategy.

\section{CONCLUSIONS}

We discuss these findings in terms of the competing explanations of the 'ego depletion' effect, as well as in terms of the trait versus state approach to self-control.

\section{KEY WORDS}

self-control trait; self-control state; regulatory strategies; ego depletion; amusement regulation

CORRESPONDING AUthor - Natalia Wójcik, Institute of Psychology, Faculty of Philosophy, Jagiellonian University, 6 Ingardena Str., 30-060 Krakow, Poland, e-mail: natt.wojcik@gmail.com

AUthors' CONTRIBUtion - A: Study design - B: Data collection - C: Statistical analysis - D: Data interpretation .

E: Manuscript preparation · F: Literature search · G: Funds collection

TO CITE THIS ARTICLE - Wójcik, N., \& Nęcka, E. (2019). Regulation strategies and their impact on subsequent response

inhibition: the moderating role of the self-control trait. Current Issues in Personality Psychology, 7(2), 132-141.

RECEIVED 05.09.2018 · REVIEWED 09.04.2019 • ACCEPTED 15.04.2019 • PUBLISHED 29.05.2019 


\section{BACKGROUND}

Self-control is the ability of humans to control thoughts, emotions and behaviour when a conflict between action tendencies occurs. The decision concerning the actual course of behaviour is tough: one action usually requires effort but leads to the fulfilment of an important goal, whereas the other corresponds to a desire that threatens this goal's achievement, yet gives an immediate reward (Duckworth \& Gross, 2014). Postponing gratification, inhibiting automatic response, or overriding innate impulses in the face of a future reward are a few examples of many self-control manifestations. Despite the fact that self-control serves people to maintain success in life (Moffit et al., 2011), most of us sometimes fail to exert control and succumb to the tendency of behaving in a more automatic or impulsive manner.

Every person pursues multiple goals simultaneously; therefore, he/she has to deal with many behavioural tendencies. Self-control requires constant integration of these tendencies with regard to possible disturbing stimuli that occur on an everyday basis. The effectiveness of this integration differs across individuals and hence constitutes an important personal trait. The self-control trait is known to be relatively stable across many situations (de Ridder, Lensvelt-Mulders, Finkenauer, Stok, \& Baumeister, 2012) and can be trained, at least in some cases (Muraven, Baumeister, \& Tice, 1999).

People differ from each other with respect to their level of self-control (Tangney, Baumeister, \& Boone, 2004). Some people are prone to being distracted by temptations and are more willing to act on them, while others are more likely to pursue their goals in a quite placid way regardless of the desires that arise. Therefore, self-control may be seen as a relatively permanent trait of personality (de Ridder et al., 2012). Individuals with a high level of self-control are more likely to experience positive life outcomes compared to those with a low level of self-control (Moffit et al., 2011). The self-control trait develops in early childhood and affects later developmental stages. For example, children who performed poorly on a delay of gratification task had more difficulties in school 10 years later than their peers who were able to wait for the reward for a longer period of time (Mischel, Shoda, \& Peake, 1988). Moreover, Duckworth and Seligman (2005) have shown that self-discipline outclasses intellectual abilities in terms of predicting academic success. Additionally, there is empirical evidence that dispositional self-control facilitates outcomes in five behavioural domains pinpointed by Tagney and her colleagues (2004): achievements, impulse control, adjustment, interpersonal relationships, and moral emotions.

In addition to the trait approach to self-control, a parallel perspective has developed which treats self- control in terms of a state (Baumeister \& Vohs, 2007). Self-control fluctuates at the intra-personal level according to the situational context (e.g., the presence of others, the intensity of desired stimuli, etc.) and the transient psychophysiological condition (e.g., being hungry). The self-control state has been thoroughly investigated since Baumeister and his colleagues proposed an 'ego depletion' model of self-control (Baumeister \& Vohs, 2007; Muraven \& Baumeister, 2000). Baumeister and Heatherton (1996) noticed that efforts in self-control in one task partially indispose exertion of self-control in the following task. This sequential task paradigm has lent support to the implication that self-control depends on some kind of mental energy that has properties resembling fuel in a car: it is limited and enables self-control to operate. On the one hand, the ego depletion effect as such was thought to be well established (Hagger, Wood, Stiff, \& Chatzisarantis, 2010; Schmeichel, 2007, but see: Hagger et al., 2016); on the other hand, the explanation proposed by the authors of its mental capacity origins are now discussed (Job, Dweck, \& Walton, 2010; Clarkson, Hirt, Jia, \& Alexander, 2010; Inzlicht \& Schmeichel, 2012; Inzlicht, Schmeichel, \& Macrae, 2014). The alternative explanations of the ego-depletion effect do not appeal to limited inner resources due to the important limitations of Baumeister's theory. Firstly, glucose, the biological substrate of the brain's energy, was claimed to be an implausible physiological basis of the ego-depletion effect (for discussion on this topic see: Kurzban, 2010; Beedie \& Lane, 2012; Kurzban, Duckworth, Kable, \& Myers, 2013). Secondly, it is relatively easy to reduce the effect by, for example, manipulating participants' beliefs about willpower without any changes in the amount of mental effort they have to exert (Job et al., 2010). To address these issues, Inzlicht and his coworkers proposed a motivational explanation for this phenomenon that is referred to as the shifting priorities model (Inzlicht \& Schmeichel, 2012; Inzlicht et al., 2014). The authors allege that the basis of ego depletion can be found in a shift in motivation and attention. Specifically, as engaging in self-control is unpleasant (mostly because it is effortful), exerting self-control reduces further motivation for tasks that are executed with a sense of duty and, at the same time, increases motivation to perform behaviours connected with personally meaningful or entertaining goals. According to the model, these shifts in motivation are strongly related to shifts in attention: it either becomes reduced to cues signalling a need for control, or it increases for cues signalling immediate reward. Therefore, participants who experience effort during one task feel more justified to not make an effort during a second task. The main statement of the shifting priorities model is that, much like fatigue (Hockey, 2011), the ego-depletion effect is caused by unwillingness instead of a real physiological incapa- 
bility. We believe that the processual model (Gross, 2002; Duckworth, Gendler, \& Gross, 2014) may contribute to understanding the mechanisms that hide underneath the ego depletion effect and tells us a little bit more about the relation between the self-control state and the self-control trait.

Given the above, it becomes clear that the selfcontrol trait is a very important personality disposition and should be taken into account as a covariant in research that aims to scrutinize self-control behaviour in diverse domains. Yet, its relationship with short-term situational changes has been poorly investigated so far. It may be assumed that dispositional self-control should guard against the negative influence of situational factors such as contact with a temptation or inner depletion (e.g. caused by previous inhibition of impulses). However, evidence in this area is scarce and even counterintuitive (Imhoff, Schmidt, \& Gerstenberg, 2014). The main aim of the present study was to investigate the relationship between the self-control state and the self-control trait in the context of emotional regulation based on metacognitive strategies. We explore the consequences of implementing different strategies of amusement regulation for the subsequent capability to halt an already prepared reaction in order to further clarify the role that self-control trait plays in the observed effect. Regulation of emotions is widely considered to be a part of self-control (Inzlicht, Bartholow, \& Hirsh, 2015; Tangney et al., 2004). The processual model of emotional regulation proposed by Gross (1998, 2002) and developed by Duckworth, Gendler and Gross $(2014,2016)$ propounds that both emotional regulation and self-control depend on metacognitive strategies that people implement in their everyday lives to counteract impulsive behaviour. These strategies are organized into five stages: (1) selection of situation, (2) modification of situation, (3) attentional deployment, (4) cognitive change, and (5) response modulation (Duckworth et al., 2014).

Amusement is certainly one of the most pleasant feelings people encounter in everyday life. Amusement, as well as other feelings connected with humour, occupies a special place in human social interactions (Hurley, Dennett, \& Adams, 2013). Humour enhances cooperation, promotes binding, and helps people to 'break the ice' (Weisfeld, 1993). It is also considered as a component in maintaining health (Martin, 2001). Nevertheless, there are circumstances under which people should not feel - or at least should not express - their amusement. Those situations include lectures, business meetings, and funerals, to name just a few. Emotion regulation studies usually focus on negative feelings, probably due to their possibly devastating influence on human behaviour and well-being. We believe that regulation of positive feelings is also a socially important issue. According to the processual model, the earlier a person implements a strategy, the more effective their emotion or behaviour management (Gross, 2002; Duckworth et al., 2014, 2016); however, humorous situations are usually unexpected. Therefore, while down-regulating their amusement, people depend on the later stage strategies proposed by the processual model: cognitive change, which is often equated with reappraisal; and response modulation, which takes the form of inhibition of the emotional response. Cognitive change consists in altering the way a situation is mentally construed so as to decrease its emotional impact, while inhibition amounts to suppression of outward signs of feelings (Gross, 2002). Cognitive change and inhibition are related to different brain activations (e.g., Vrtička, Sander, \& Vuilleumier, 2011), and usually the former appears to be more effective than the latter (Gross, 2002; Ochsner \& Gross, 2005). The aim of this research is to examine whether and how trait self-control and metacognitive strategies interact and to scrutinize their relation to possible shortterm consequences of overcoming amusement (i.e., ego depletion).

The predictions that motivated our study are as follows. If the resource model (Baumeister \& Vohs, 2007) is valid, amusement regulation should impair subsequent acts of self-control, regardless of the adopted strategy. Both cognitive change and modulation involve mental effort and activate large brain structures, mostly the prefrontal cortex (PFC; Goldin, McRae, Ramel, \& Gross, 2008; Korb, Grandjean, Samson, Delplanque, \& Scherer, 2012; Vrtička et al., 2011), and therefore both these strategies depend on the brain's energy resources. However, cognitive change consists in cognitive manipulation that entails goal shifting and attention deployment; rather than focusing on the undesirable response, one has to focus on cognitive aspects of the situation (Inzlicht et al., 2014; Korb et al., 2012). If the motivational stance is valid (e.g., Inzlicht \& Schmeichel, 2012), cognitive change should have a smaller negative impact than response inhibition for subsequent acts of self-control. Both cognitive change and inhibition should decrease the funniness of humorous stimuli; yet, unlike inhibition, cognitive change should be sufficient to foil self-regulatory failure. Additionally, we intended to determine whether self-control understood as a personal trait (Tangney et al., 2004; Moffit et al., 2011) would show any moderating influence on the predicted effects. Some people are more prone to ceasing their self-control effort than others. It has been proposed that the self-control trait may be linked more to adaptive customs and habits than to resisting single temptations (de Ridder et al., 2012). On that account, we assume that the self-control trait should reveal its influence especially under conditions in which the default strategy is poor (i.e., inhibition). 


\section{PARTICIPANTS AND PROCEDURE}

\section{PARTICIPANTS}

Forty-seven females and 43 males $(N=90)$ participated in exchange for $20 \mathrm{PLN}(\approx 5 €)$. Due to missing information in the questionnaires, five participants were excluded from further analyses, leaving a total of 85 (46 females), age 21-35 $(M=23.26, S D=2.26)$. Participants were volunteers recruited by an Internet advertisement. The candidates were told that the purpose of the study was to investigate different aspects of perception. Participants were randomly assigned to three groups, according to the experimental manipulation described in the Procedure section.

\section{TESTS AND MATERIALS}

Cartoons. We used 60 supposedly funny cartoons. They were carefully chosen from 200 humorous pictures found on the web. These 200 cartoons were subjected to the pilot study, in which the participants $(N=30)$ were asked to rate them on the basis of being more or less funny. All cartoons were ranked according to the assessed humorous value; we chose the top 60 pictures as stimuli in this experiment.

Stop signal task. Participants performed the stop signal task (Logan, 1994) modified by Senderecka and her co-workers (Senderecka, Grabowska, Szewczyk, Gerc, \& Chmylak, 2012). Pictures of an airplane heading left or right served as the visual stimuli in this version of the SST. Participants were asked to press the left or right arrow keys according to the direction of the plane. They were instructed to be as fast and correct as possible. These go stimuli were randomly presented one at a time, each with $50 \%$ probability. On $25 \%$ of trials, an auditory stop signal was presented over headphones; it alerted participants to inhibit their response to the primary go stimulus, regardless of the direction of the plane. After successful inhibition, the interval between the go and stop stimuli became 50 ms longer; after unsuccessful inhibition the interval became $50 \mathrm{~ms}$ shorter (min. $150 \mathrm{~ms}$, max. $400 \mathrm{~ms}$ ). At the start of the experiment the stop-signal delay was $150 \mathrm{~ms}$. The SSRT (stop signal reaction time) was calculated by subtracting the critical $50 \%$ stop-signal delay latency from the mean primary go task reaction time, which was estimated from correct no-signal trials. The shorter the SSRT, the better the ability to inhibit the unnecessary response.

NAS-50 self-control questionnaire. For self-control assessment, we used the NAS-50 questionnaire developed by Nęcka et al. (2016). It measures general trait self-control and its five components, represented by the following subscales: Initiative and Persistence, Proactive Control, Switching and Flexibility,
Goal Maintenance, and Inhibition and Adjournment. The validation study, run with the participation of 930 people, revealed good internal consistency of this questionnaire (Cronbach's $\alpha=.86$ ), as well as a high level of stability in the test-retest evaluation (intraclass correlation coefficient, ICC $=.94$ ). Moreover, NAS-50 showed positive correlations with other measures of self-control, including Tangney, Baumeister and Boone's Self-Control Scale $(r=.76$, $p<.001$; Tangney et al., 2004), and a lack of correlation with intelligence test scores.

\section{PROCEDURE}

Sequence of events. Participants entered the computer lab in groups (from 3 to 6 persons). The experimenter was always present in the lab during the whole procedure. In the first part of the experiment, participants completed two questionnaires: the UWIST Mood Adjective Checklist (UMACL; Matthews, Jones, \& Chamberlain, 1990) and NAS-50. In the second part of the procedure, participants were presented with 60 humorous pictures that appeared on the screen one by one (Task 1). Their task was to rate each cartoon by pressing appropriate keys. Possible ratings were as follows: 1 - not funny at all, 2 - a bit funny, 3 - funny, 4 - very funny. Every single cartoon was presented immediately after a participant had rated the previous one. At the end of the experiment, all participants performed the Stop Signal Task (Task 2).

Manipulation. Participants were randomly assigned to one of three emotion regulation conditions: inhibition, cognitive change, and control. In the inhibition condition, the participants $(N=29)$ were instructed to suppress their amusement and laughter. In order to make them inhibit amusement, we presented them with the following instruction: "The aim of the experiment is to check how suppression of amusement influences other cognitive abilities. Therefore, you are asked to suppress your amusement while looking at the pictures on the screen. You should suppress external symptoms of amusement (facial expressions, laughter, body movements) as well as inner amusement". In the cognitive change condition, participants $(N=27)$ were instructed to play the role of a reviewer, according to the following instruction: "The aim of the experiment is to check how critical analysis influences other cognitive abilities. Therefore, you are asked to try to impersonate an art critic. You should think about the good and bad features of each picture presented on the screen, considering different values such as aesthetics, humour, ethics, etc." The main purpose of the instruction was to implement a strategy that would help participants to have a serious attitude towards the presented pictures (role of art critic) and thus en- 
able them to appraise other factors, rather than only the humorous value of the pictures. In the control condition, participants $(N=29)$ were told just the following: "The aim of the experiment is to check how watching some less or more humorous pictures influences other cognitive abilities”.

\section{RESULTS}

\section{AMUSEMENT REGULATION}

Our first goal was to assess whether the amusement regulation strategy, or lack thereof, affected the cartoon ratings. The dependent variable (DV) was calculated as the sum of the ratings of all pictures presented to every participant. A one-way ANOVA revealed significant differences between groups, presented in Table 1, upper row $\left(F(2,82)=8.53, p<.001, \eta^{2}=0.17\right)$. Tukey's post hoc tests showed that inhibition $(p<.001)$ and cognitive change $(p=.009)$ decreased the ratings of humorous pictures, in comparison to the control group. There were no significant differences between the inhibition and cognitive change conditions. We did not find any significant relations between the mood of the participants (measured by UMACL) and the ratings of the humorous pictures.

\section{EGO DEPLETION}

Next, we looked at the ego-depletion effect. We hypothesized that using the modulation strategy (inhibition) during Task 1 would cause the depletion effect in Task 2, whereas the cognitive change strategy would not. This hypothesis was tested by performance in the Stop Signal Task and SSRT as its basic dependent variable. This DV was log transformed in order to normalize its distribution. We expected that participants in the cognitive change and control group would demonstrate better performance (shorter SSRT) than participants in the inhibition group. This hypothesis was not proven (see: Table 1, lower row). The one-way ANOVA on mean SSRT revealed significant differences between groups $(F(2,82)=3.40$,

Table 1

Total scores of funniness and mean SSRT in three groups

\begin{tabular}{lccc}
\hline & Control & Inhibition & $\begin{array}{c}\text { Cognitive } \\
\text { change }\end{array}$ \\
\hline $\begin{array}{l}\text { Funniness } \\
\text { scores }\end{array}$ & 148.31 & 121.55 & 127.33 \\
SSRT $(\mathrm{ms})$ & 234.62 & 232.93 & 212.26 \\
\hline Note. SSRT is stop signal reaction time.
\end{tabular}

$\left.p=.038, \eta^{2}=0.08\right)$. Tukey's post hoc tests revealed that despite the fact that SSRT scores in the inhibition group $(M=232.93, S D=42.07)$ were worse than those in the cognitive change group $(M=212.26$, $S D=29.44)$, this difference did not reach the level of significance $(p=.089)$. Unexpectedly, the post-hoc analysis showed significant differences between the cognitive change and the control group $(p=.048)$, and no significant differences between the control and the inhibition group. Thus, the control group subjects obtained unpredictably poor scores in SST although they were not required to regulate amusement.

\section{THE MODERATING INFLUENCE OF THE SELF-CONTROL TRAIT ON THE SELF-CONTROL STATE}

To test our hypotheses regarding the self-control trait, we ran moderation analyses with the Process macro (version 2.16.3) for SPSS. SSRT was the dependent variable and trait self-control (SCT) was the moderator. To keep SCT as a continuous variable, we used a method proposed by Hayes and Montoya (2017) that allows an interaction with a multi-categorical variable to be tested and probed (here: the experimental condition) in linear regression analysis. We performed Helmert coding. Therefore, $\mathrm{D}_{1}$ and $\mathrm{D}_{2}$ were created and regressed on SSRT (log-transformed), where $b_{1}$ estimates the mean difference in SSRT between the control group and the unweighted mean of the means for the Inhibition and cognitive change groups; $b_{2}$ estimates the difference between the means of the Inhibition group and the cognitive change group. The tested model was significant $R^{2}=.19, F(5,79)=3.64$, $p=.005$. The results revealed a significant interaction between $\mathrm{D}_{1}$ and SCT $(b=-0.01, S E=0.001, t=-2.26$, $p=.026)$, yet $\Delta R$ did not reach the level of significance $(p=.074)$. We looked at the conditional effect of group condition $\left(\mathrm{D}_{1}\right.$ and $\left.\mathrm{D}_{2}\right)$ on SSRT at the specific values of SCT (moderator): $M$ and $\pm 1 S D$. The results showed that there is no influence of the experimental condition (for both $\mathrm{D}_{1}$ and $\mathrm{D}_{2}$ ) at the low level of the moderator $(-1 S D)$. At the mean level of the moderator, the difference between the mean in the control group and the mean of the means in both experimental groups $\left(\mathrm{D}_{1}\right)$ was insignificant; however, the difference between the Inhibition and Cognitive change condition $\left(\mathrm{D}_{2}\right)$ had a significant influence on DV $\left(b_{2}=-0.04\right.$, $S E=0.02, t=-2.16, p=.033)$. A test of equality of conditional means at the mean value of the moderator revealed $\Delta R=.07, F(2,79)=3.49, p=.035$. At a high value of the moderator $(+1 S D), \mathrm{D}_{1}$ had a significant influence on DV $\left(b_{1}=-0.06, S E=0.02, t=-2.60\right.$, $p=.011)$. A test of equality of conditional means at the mean value of the moderator revealed $\Delta R=0.09$, $F(2,79)=4.21, p=.018$, whereas $\mathrm{D}_{2}$ did not have a significant influence on DV. 
To illustrate the model (Figure 1), we chose values of the moderator (SCT) corresponding to the sample mean $(M=158.84)$ and one standard deviation $(S D=14.82)$ above the mean (176.65) and below the mean (144.02), as suggested by Hayes and Montoya (2017). Our question is whether the effect of condition on SSRT varies depending on SCT. Therefore, our interest is in the gap between the lines at the presented values of SCT on the horizontal axis, not in the different slopes of the lines. The gap between the lines conditioned at a specific value of SCT indicates the presence or absence of differences in SSRT as a result of adopting different strategies of emotional regulation. As we can see, at the low level of SCT ( 144) the differences are not significant. At the medium level of SCT ( 158), there is a significant difference between inhibition and cognitive change groups $(p=.035)$. On one hand, at the high level of SCT ( 177) there is a significant difference between the unweighted mean of the Inhibition and cognitive change groups and the control group $(p=.011)$; on the other hand, no differences between the inhibition and cognitive change groups were significant at this level of the trait of self-control.

\section{DISCUSSION}

We presented participants with funny cartoons (Task 1) and asked them either to play the role of an art critic (cognitive change strategy) or just to abstain from laughter and amusement (inhibition strategy). The control group subjects were instructed to just enjoy the cartoons (spontaneous condition, Korb et al., 2012). We found that both strategies lowered the funniness of the cartoons. We also found that the ego-depletion effect occurred in Task 2 among participants with low self-control as a trait in the inhibition group. Cognitive change did not produce such a depleting effect, regardless of the participants' level of the self-control trait.

Numerous studies using the sequential task paradigm have shown detrimental effects of emotion regulation on the efficacy of subsequently exerted cognitive control (e.g., Gray, 2001; Johns, Inzlicht, \& Schmader, 2008; Hofmann, Rauch, \& Gawronski, 2007; Schmeichel, Caskey, \& Hicks, 2015). These effects have not yet been directly checked for amusement and humour, so the present study fills this gap using humorous stimuli in Task 1 . The results confirmed the prediction that implementing regulation strategies such as suppression (inhibition) or cognitive change reduces ratings of humorous stimuli. This result is in line with previous findings on the influence of emotional regulation on reducing the subjective feeling of positive emotions (Gross, 2002; Korb et al., 2012). Notably, there were no significant differences between ratings in the suppression and

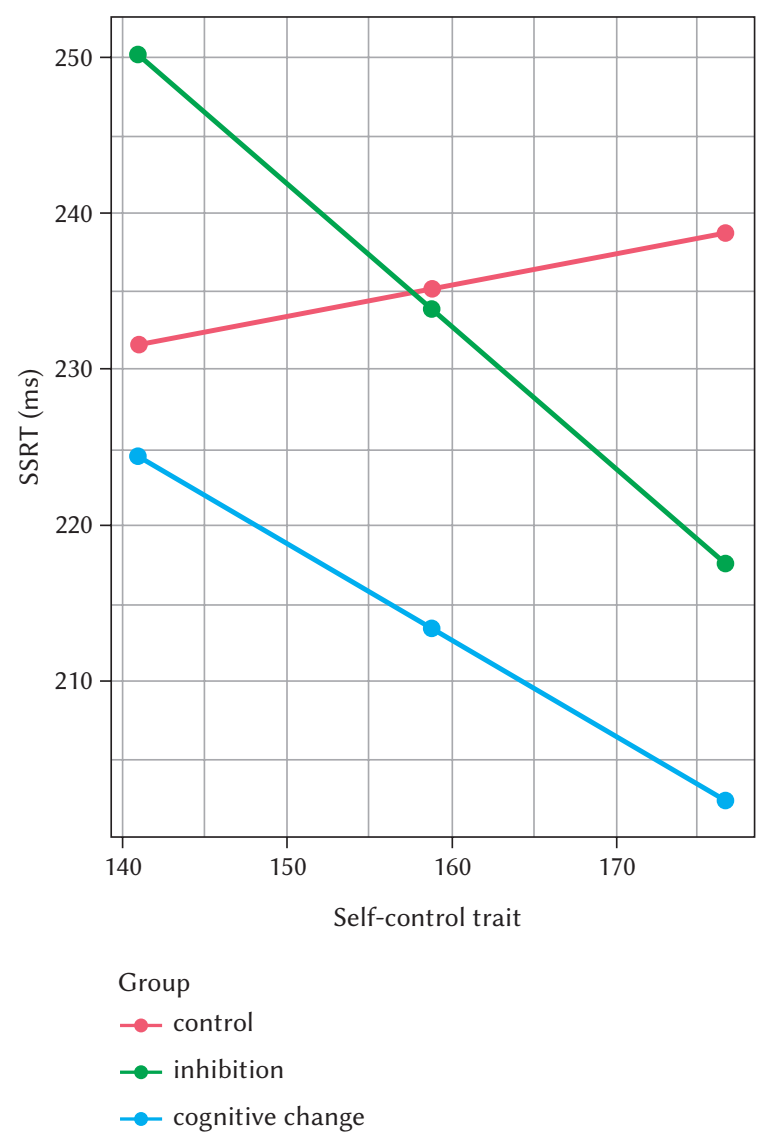

Figure 1. Stop signal reaction time (SSRT) by condition, depending on the trait self-control.

cognitive change conditions, which may suggest that cognitive change is not a superior strategy to modulation. On the other hand, cognitive change may still be a better strategy in terms of the amount of required effort and its suitability for sustaining goal-oriented motivation (Milyavskaya, Inzlicht, Hope, \& Koestner, 2015; Gergelyfi, Jacob, Olivier, \& Zénon, 2015). In that case, the lack of differences between groups should not be surprising, though we should expect differences in subsequent control-demanding tasks (Task 2).

This prediction has not been confirmed directly since participants who applied the cognitive change strategy did not demonstrate better control in the SST than the inhibition group. As a matter of fact, this difference occurred but did not reach the level of statistical significance $(p=.089)$. This result is in line with recent reports that the ego-depletion effect size is small or close to zero (Carter \& McCullough, 2014; Hagger et al., 2016). However, participants from the control group (spontaneous condition) obtained poor results in the SST (significantly worse than participants from the cognitive change group), although they were not supposed to control anything in Task 1. These findings may be surprising, as long as we do not consider the possibility that participants in the 
control group might have modulated their emotions similarly to participants in the inhibition group, even though they were not asked to do so. A psychological experiment feels like an official situation; therefore it can influence participants' behaviour without the researcher's intention (Nichols \& Maner, 2008). Thus, participants in the control group might have tried to silently inhibit their amusement so as not to interrupt others or attract the experimenter's attention. Emotional regulation might have been more difficult for them than for participants in the other groups because - unlike the other conditions - they did not receive any advice on how to control their amusement properly. In fact, a situation that both amuses us and forbids us from showing our amusement makes it particularly funny (e.g., Robins \& Vandree, 2009). So, we can suppose that participants from the control group had a tougher task than those in the inhibition group. Having received an instruction to suppress amusement might have eased the task for the inhibition group, who had a certain exercise to do. By contrast, participants in the control group were in a much more natural situation. They were watching humorous stimuli surrounded by other people, who they should not have interrupted for the sake of the 'dignity' of a scientific experiment. The inhibition group had in mind that the necessity to suppress reactions related to amusement had arisen from the instruction, not from the situation itself; therefore they could not have experienced an increased feeling of amusement because they did not attribute the sensation of effort (that stemmed from constant inhibition) to the humorous value of the stimuli. This may be why the inhibition group gave lower funniness ratings to the pictures than the control group. All in all, participants from both the control and the inhibition group had to put effort into controlling their emotional reaction, which led to worse performance in Task 2. Participants in the cognitive change group, thanks to the analysing strategy, might have seen the task as less effortful than the other groups, which resulted in better performance in the SST.

The results revealed that the self-control trait had a moderating impact on SST performance. There were no differences in SST performance between the groups if weak self-controllers are considered (-1 SD below the mean). However, increasing levels of the self-control trait displayed differences in SST performance, depending on the condition. For medium level self-controllers, we observed a difference in favour of the latter between the inhibition group and the cognitive change group. This difference disappeared for good self-controllers: participants from the inhibition group performed as well as in Task 2 as those from the cognitive change group if their level of self-control trait was relatively high $(+1 S D$ above the mean). Still, both experimental groups outperformed the control group in the case of good self- controllers. Individual differences in the self-control trait are possibly related to disparate strategies of coping (Baumeister \& Vohs, 2007). In the inhibition group, participants with weaker self-control could regulate emotions that had already occurred; hence they had to put more effort into inhibiting all signs of ongoing emotion. In contrast, participants with stronger self-control could have deduced from the instruction that they would have to manage their emotions picture by picture and therefore might have more or less automatically implemented the guarding strategy (like the cognitive change approach) to complete the task. This notion is consistent with the two-stage model of self-control proposed by Myrseth and Fishbach (2009), which propounds that effective self-control depends on knowing both when to exert control (detecting conflict) and what to exert (a good strategy). This hypothetical tendency would explain the similarity in SST performance between good self-controllers in the inhibition group and good selfcontrollers in the cognitive change group. The basic conclusion may be that people with high self-control might have developed, and automatized through experience, better strategies to deal with manifold situations that require coping with emotions and impulsive behaviour (Duckworth et al., 2016; Hofmann, Schmeichel, \& Baddeley, 2012).

The suggested inference requires taking into consideration the reason that the self-control trait did not protect participants in the control group (we suggested previously that the control group might have had somewhat similar conditions as the inhibition group), which was previously believed to render similar conditions as the inhibition group. It seems crucial that, according to the instruction, participants in the control group did not have to (or even were not allowed to) regulate their emotions systematically. They could only spontaneously remark that it would be better to suppress the external symptoms of amusement so that they did not disturb other participants in the lab. The instruction informed them that they would see pictures that had various levels of funniness; therefore, they should not have implemented emotional regulation before the emotion occurred because it would have made them unable to properly rate the stimuli. It is also worth noting that the strategy of cognitive change did not work for the very low self-controllers, who performed equally poorly in Task 2 regardless of the strategy. We propose two possible explanations for this result. One is that poor self-controllers need more than just a brief instruction to properly implement a cognitive change strategy, as they are not used to using such strategies in their everyday lives. Another explanation is that poor self-controllers have weak executive functions (EF; Hofmann et al., 2012), so they perform tasks requiring EF engagement (here: SST) at a level at which it is not possible to improve it. We did not control for 
participants' executive functions capacity; therefore, we cannot unequivocally resolve this issue.

All in all, the present study partially replicated the results of previous research: it indicates that exerting self-control in the first task worsens self-control performance in the following task (see: Baumeister \& Heatherton, 1996; Baumeister \& Vohs, 2007; Hagger et al., 2010). The results highlight the importance of including trait self-control into analysis of the effect. At first glance, the results may contribute to both the resource and the motivational explanations of self-control. However, it should be noted that what prevented the ego depletion effect was a good regulation strategy, not minimizing the amount of mental processes required by a task; otherwise the results would be consistent with the resource model. Moreover, we can safely assume that critical analysis requires even more mental processes than inhibition of laughter, yet it may seem less effortful for people to reappraise the situation than to modulate ongoing emotions. Hopefully, simple suggestions that comprise good self-control strategies may help weaker (but not very weak) self-controllers to abstain from succumbing to temptations and enable them to act similarly to good self-controllers. This line of reasoning is consistent with Inzlicht et al.'s (2014) explanation of the ego depletion effect. These authors emphasize that the state of ego depletion works through mental fatigue, which resembles an emotion and leads to shifts in motivation and attention from obligations to rewards. In the case of laboratory experiments, a reward may simply boil down to the promise of free time, that is, finishing a tedious task (Inzlicht et al., 2014; Milyavskaya et al., 2015). This issue has been raised by Evans, Boggero, and Segerstrom (2016), who posit that if mental fatigue, similarly to emotions, has an informative function rather than being a consequence of ongoing physiological changes and energy depletion, it would be prone to changes induced by emotion regulation strategies.

In considering the results of this study, we should emphasize its important limitations. Namely, the sample size was large enough to detect the predicted moderation (as it was tested to be sufficient to detect a medium effect size $f=.30$ based on a priori power analysis using $G^{*}$ Power software; the power analysis revealed that a sample of 90 participants was needed to obtain statistical power at the level 0.80 ), yet it was rather small, and further studies should increase the number of participants to replicate the results because the ego-depletion effect solely is sometimes reported as small (Hagger et al., 2010). Another limitation pertains to the fact that our research tackles the problem of ego depletion only at the proximate level of explanation (Inzlicht et al., 2014), which pertains to the hypothetical processes responsible for worsening of performance in the second task. The ultimate explanation, on which we did not focus, may be phrased in the question 'Why are there such limits?' There are competing accounts on this issue also. In short, one conception propounds that people are energetic misers and they (over)economize on their resources, thus they are very sensitive to every engagement in action (Evans et al., 2016). The opposite idea establishes the problem as an evolutionary adaptation: humans had to develop a system which enabled them to maintain a balance between exploiting possessed rewards and exploring the environment for new opportunities (Inzlicht et al., 2014). Although our findings cannot give a direct answer to the ultimate account, we believe they do contribute to the proximate account by taking into consideration the processual model of self-control and the moderating effects of the self-control trait. Given the above limitations, we believe that future studies would benefit from taking into consideration the ultimate account by exploring the universal causes of the shifting motives to exert self-control. As for an individual differences perspective on selfcontrol research, it will be also of great importance to include in further studies the measurement of the trait self-control while manipulating other factors that may possibly render motivation shift effects (possible manipulations to explore: e.g. varying financial incentives for performance; the difficulty of tasks; implementation of other regulatory strategies such as mindfulness-based or attentional-deployment techniques). Taking into account participants' trait self-control could reveal that some manipulations work only among participants with (under)developed self-control abilities, and therefore provide a crucial insight into understanding of the nature of self-control and also give a compelling background for practical interventions.

All in all, we hope that our results shed light on understanding the relationship between the selfcontrol state and the self-control trait and their interplay with self-control strategies. As Inzlicht and Schmeichel (2012) stated, it is valuable to integrate models of self-control so as to begin to develop a unified view of this crucial psychological construct.

\section{ACKNOWLEDGMENTS}

The study was financed by the National Science Centre in Poland $(\mathrm{NCN})$ on the basis of decision number DEC-2013/08/A/HS6/00045.

\section{REFERENCES}

Baumeister, R. F., \& Heatherton, T. (1996). Self-regulation failure: An overview. Psychological Inquiry, 7, 1-15. 
Baumeister, R. F., \& Vohs, K. D. (2007). Self-regulation, ego depletion, and motivation. Social and Personality Psychology Compass, 1, 115-128.

Beedie, C. J., \& Lane, A. M. (2012). The role of glucose in self-control another look at the evidence and an alternative conceptualization. Personality and Social Psychology Review, 16, 143-153.

Carter, E. C., \& McCullough, M. E. (2014). Publication bias and the limited strength model of selfcontrol: Has the evidence for ego depletion been overestimated? Frontiers in Psychology, 5, 823.

Clarkson, J. J., Hirt, E. R., Jia, L., \& Alexander, M. B. (2010). When perception is more than reality: the effects of perceived versus actual resource depletion on self-regulatory behavior. Journal of Personality and Social Psychology, 98, 29-46.

de Ridder, D. T., Lensvelt-Mulders, G., Finkenauer, C., Stok, F. M., \& Baumeister, R. F. (2012). Taking stock of self-control: A meta-analysis of how trait selfcontrol relates to a wide range of behaviors. Personality and Social Psychology Review, 16, 76-99.

Duckworth, A. L., Gendler, T. S., \& Gross, J. J. (2014). Self-control in school-age children. Educational Psychologist, 49, 199-217.

Duckworth, A. L., Gendler, T. S., \& Gross, J. J. (2016). Situational strategies for self-control. Perspectives on Psychological Science, 11, 35-55.

Duckworth A. L., \& Gross J. J. (2014). Self-control and grit: Related but separable determinants of success. Current Directions in Psychological Science, 23, 319-325.

Duckworth, A. L., \& Seligman, M. E. P. (2005). Selfdiscipline outdoes IQ in predicting academic performance of adolescents. Psychological Science, 16, 939-944.

Evans, D. R., Boggero, I. A., \& Segerstrom, S. C. (2016). The nature of self-regulatory fatigue and "ego depletion" lessons from physical fatigue. Personality and Social Psychology Review, 20, 291-310.

Gergelyfi, M., Jacob, B., Olivier, E., \& Zénon, A. (2015). Dissociation between mental fatigue and motivational state during prolonged mental activity. Frontiers in Behavioral Neuroscience, 9, 1-15.

Goldin, P. R., McRae, K., Ramel, W., \& Gross, J. J. (2008). The neural bases of emotion regulation: Reappraisal and suppression of negative emotion. Biological Psychiatry, 63, 577-586.

Gray, J. R. (2001). Emotional modulation of cognitive control: Approach-withdrawal states double-dissociate spatial from verbal two-back task performance. Journal of Experimental Psychology: General, 130, 436-452.

Gross, J. J. (1998). The emerging field of emotion regulation: an integrative review. Review of General Psychology, 2, 271-299.

Gross, J. J. (2002). Emotion regulation: Affective, cognitive, and social consequences. Psychophysiology, 39, 281-291.
Hagger, M. S., Wood, C., Stiff, C., \& Chatzisarantis, N. L. (2010). Ego depletion and the strength model of self-control: a meta-analysis. Psychological Bulletin, 136, 495-525.

Hagger, M. S., Chatzisarantis, N. L. D., Alberts, H., Anggono, C. O., Batailler, C., Birt, A. R., ... Zwienenberg, M. (2016). A multilab preregistered replication of the ego-depletion effect. Perspectives on Psychological Science, 11, 546-573.

Hayes, A. F., \& Montoya, A. K. (2017) A Tutorial on testing, visualizing, and probing an interaction involving a multicategorical variable in linear regression analysis. Communication Methods and Measures, 11, 1-30.

Hockey, G. R. J. (2011). A motivational control theory of cognitive fatigue. In L. P. Ackerman (Ed.), Cognitive Fatigue: Multidisciplinary Perspectives on Current Research and Future Applications (pp. 167-197). Washington, DC: American Psychological Association.

Hofmann, W., Rauch, W., \& Gawronski, B. (2007). And deplete us not into temptation: Automatic attitudes, dietary restraint, and self-regulatory resources as determinants of eating behavior. Journal of Experimental Social Psychology, 43, 497-504.

Hofmann, W., Schmeichel, B. J., \& Baddeley, A. D. (2012). Executive functions and self-regulation. Trends in Cognitive Sciences, 16, 174-180.

Hurley, M. M., Dennett, D. C., \& Adams, R. B. (2013). Inside jokes. Using humor to reverse-engineer the mind. Cambridge, MA: MIT Press.

Imhoff, R., Schmidt, A. F., \& Gerstenberg, F. (2014). Exploring the interplay of trait self-control and ego depletion: Empirical evidence for ironic effects. European Journal of Personality, 28, 413-424.

Inzlicht, M., Bartholow, B. D., \& Hirsh, J. B. (2015). Emotional foundations of cognitive control. Trends in Cognitive Sciences, 19, 126-132.

Inzlicht, M., \& Schmeichel, B. J. (2012). What is ego depletion? Toward a mechanistic revision of the resource model of self-control. Perspectives on Psychological Science, 7, 450-463.

Inzlicht, M., Schmeichel, B. J., \& Macrae, C. N. (2014). Why self-control seems (but may not be) limited. Trends in Cognitive Sciences, 18, 127-133.

Job, V., Dweck, C. S., \& Walton, G. M. (2010). Ego depletion - Is it all in your head? Implicit theories about willpower affect self-regulation. Psychological Science, 21, 1686-1693.

Johns, M., Inzlicht, M., \& Schmader, T. (2008). Stereotype threat and executive resource depletion: examining the influence of emotion regulation. Journal of Experimental Psychology: General, 137, 691-705.

Korb, S., Grandjean, D., Samson, A. C., Delplanque, S., \& Scherer, K. R. (2012). Stop laughing! Humor perception with and without expressive suppression. Social Neuroscience, 7, 510-524. 
Kurzban, R. (2010). Does the brain consume additional glucose during self-control tasks? Evolutionary Psychology, 8, 244-259.

Kurzban, R., Duckworth, A., Kable, J. W., \& Myers, J. (2013). An opportunity cost model of subjective effort and task performance. Behavioral and Brain Sciences, 36, 661-679.

Logan, G. D. (1994). On the ability to inhibit thought and action: A user's guide to the stop signal paradigm. In D. Dagenbach \& T. H. Carr (Eds.), Inhibitory processes in attention, memory, and language (pp. 189-239). San Diego: Academic Press.

Martin, R. A. (2001). Humor, laughter, and physical health: Methodological issues and research findings. Psychological Bulletin, 127, 504-519.

Matthews, G., Jones, D. M., \& Chamberlain, A. G. (1990). Refining the measurement of mood: The UWIST Mood Adjective Checklist. British Journal of Psychology, 81, 17-42.

Milyavskaya, M., Inzlicht, M., Hope, N., \& Koestner, R. (2015). Saying "no" to temptation: Want-to motivation improves self-regulation by reducing temptation rather than by increasing self-control. Journal of Personality and Social Psychology, 109, 677-693.

Mischel, W., Shoda, Y., \& Peake, P. K. (1988). The nature of adolescent competencies predicted by preschool delay of gratification. Journal of Personality and Social Psychology, 54, 687-696.

Moffitt, T. E., Arseneault, L., Belsky, D., Dickson, N., Hancox, R. J., Harrington, H., Houts, R., Poulton, R., Roberts, B. W., Ross, S., Sears, M. R., Thomson, W. M., \& Caspi, A. (2011). A gradient of childhood self-control predicts health, wealth, and public safety. Proceedings of the National Academy of Sciences, 108, 2693-2698.

Muraven, M., \& Baumeister, R. F. (2000). Self-regulation and depletion of limited resources: Does selfcontrol resemble a muscle? Psychological Bulletin, 126, 247-259.

Muraven, M., Baumeister, R. F., \& Tice, D. M. (1999). Longitudinal improvement of self-regulation through practice: Building self-control through repeated exercise. Journal of Social Psychology, 139, 446-457.

Myrseth, K. O. R., \& Fishbach, A. (2009). Self-control a function of knowing when and how to exercise restraint. Current Directions in Psychological Science, 18, 247-252.

Nęcka, E., Wujcik, R., Orzechowski, J., Gruszka, A., Janik, B., Nowak, M., \& Wójcik, N. (2016). NAS-50 and NAS-40: New scales for the assessment of selfcontrol. Polish Psychological Bulletin, 47 346-355.

Nichols, A. L., \& Maner, J. K. (2008). The good-subject effect: Investigating participant demand characteristics. The Journal of General Psychology, 135, 151-166.

Ochsner, K. N., \& Gross, J. J. (2005). The cognitive control of emotion. Trends in Cognitive Sciences, 9, 242-249.
Robbins, B. D., \& Vandree, K. (2009). The self-regulation of humour expression. A mixed method, phenomenological investigation of suppressed laughter. The Humanistic Psychologist, 37, 49-78.

Schmeichel, B. J. (2007). Attention control, memory updating, and emotion regulation temporarily reduce the capacity for executive control. Journal of Experimental Psychology: General, 136, 241-255.

Schmeichel, B. J., Caskey, R., \& Hicks, J. A. (2015). Rational versus experiential processing of negative feedback reduces defensiveness but induces ego depletion. Self and Identity, 14, 75-89.

Senderecka, M., Grabowska, A., Szewczyk, J., Gerc, K., \& Chmylak, R. (2012). Response inhibition of children with ADHD in the stop-signal task: An eventrelated potential study. International Journal of Psychophysiology, 85, 93-105.

Tangney, J. P., Baumeister, R. F., \& Boone, A. L. (2004). High self-control predicts good adjustment, less pathology, better grades, and interpersonal success. Journal of Personality, 72, 271-324.

Vrtička, P., Sander, D., \& Vuilleumier, P. (2011). Effects of emotion regulation strategy on brain responses to the valence and social content of visual scenes. Neuropsychologia, 49, 1067-1082.

Weisfeld, G. E. (1993). The adaptive value of humor and laughter. Ethology and Sociobiology, 14, 141-169. 